IdeAs

Idées d'Amériques

$14 \mid 2019$

Populismes dans les Amériques

\title{
Populismos nas Américas
}

Luc Capdevila, François Vergniolle de Chantal e Jean-Christian Vinel

Tradutor: Alice Ferreira Fernandes

\section{OpenEdition}

\section{Journals}

Edição electrónica

URL: http://journals.openedition.org/ideas/6968

DOI: $10.4000 /$ ideas.6968

ISSN: 1950-5701

\section{Editora}

Institut des Amériques

Refêrencia eletrónica

Luc Capdevila, François Vergniolle de Chantal e Jean-Christian Vinel, « Populismos nas Américas », IdeAs [Online], 14 | 2019, posto online no dia 01 outubro 2019, consultado o 24 setembro 2020. URL http://journals.openedition.org/ideas/6968 ; DOI : https://doi.org/10.4000/ideas.6968

Este documento foi criado de forma automática no dia 24 setembro 2020.

\section{c) (†) $\Theta$}

IdeAs - Idées d'Amériques est mis à disposition selon les termes de la licence Creative Commons Attribution - Pas d'Utilisation Commerciale - Pas de Modification 4.0 International. 


\title{
Populismos nas Américas
}

\author{
Luc Capdevila, François Vergniolle de Chantal e Jean-Christian Vinel \\ Tradução : Alice Ferreira Fernandes
}

1 Ao longo da última década, o populismo surgiu como um conceito muitas vezes fundamental na análise da evolução política e social num grande número de países europeus e americanos. No entanto, o seu uso continua sendo muito negativo pois, na maioria das vezes, se refere a um apelo direto ao povo baseado no ressentimento contra as elites e/ou certos grupos sociais, ao mesmo tempo que defende um arsenal de medidas "simples" e demagógicas. Ele é aliás usado principalmente para denunciar seus inimigos e há muito poucos responsáveis políticos - com exceção de Jean-Luc Mélenchon da France Insoumise, Hugo Chavez, ou os líderes do Podemos na Espanha (Chazel L., 2019) - que reivindicam este rótulo com orgulho ${ }^{1}$. Em outras palavras, o populismo é percebido antes de tudo como uma forma degradada da vida democrática. É nesse sentido que a análise de Pierre Rosanvallon (2011) enxerga nele uma tripla simplificação: primeiro, uma simplificação política ao opor um povo sonhador e homogêneo às elites corruptas; segundo, uma simplificação institucional ao rejeitar qualquer contrapeso à vontade popular; e, finalmente, uma simplificação social, que atribui ao povo uma identidade clara e definida ${ }^{2}$.

2 Mas o populismo é também uma noção com práticas e estilos muito diferentes. Nas Américas, o populismo tem sido usado recentemente para se referir a uma grande variedade de correntes e sensibilidades políticas, fazendo referência a movimentos, atores e até mesmo governos como Occupy Wall Street, Tea Party, Bernie Sanders e Donald Trump.

3 No hemisfério sul, este é particularmente o caso de regimes que também são chamados de nacionais-populares na América Latina: a Venezuela Chavista, a Bolívia dirigida por Evo Morales, a Argentina sob os governos de Kirchner...; ao mesmo tempo o termo populismo também é usado para designar correntes ultra-conservadoras, como a encarnada por Jair Bolsonaro, atual presidente do Brasil, ou os governos neoliberais dos anos 90 (Fujimori no Peru, Collor de Mello no Brasil, Bucaram no Equador...). Estes governos, liderados todos por "homens fortes" eleitos em contextos de crise política, resgataram práticas de apelo ao povo, de contato imediato com a sociedade através de 
novos procedimentos (pela televisão, por exemplo na década de 1990, e hoje por meios digitais), de poder fortemente incorporado, às vezes diretamente proveniente de antigas organizações populistas (Menem na Argentina). Mas, ao abandonar as políticas de intervenção redistributiva e econômica, características dos "velhos populismos da América Latina", eles estariam participando dos "neopulismos" definidos com base na "fusão entre populismo e neoliberalismo" negociados por eles (Freindenberg F., 2007).

Nestas condições, muitos se negam a reconhecer qualquer conteúdo à noção de populismo: o populismo não sendo uma ideologia, ele é, portanto, reduzido aos seus múltiplos usos. A ubiquidade mascara de fato uma certa confusão conceitual (Mudde C., 2007, Hermet G., 2001, Taguieff P.-A., 1997, Laclau E., 2008), especialmente porque o populismo parece ser a sombra da democracia (Arditi B., 2004, Canovan M., 1999). Embora o populismo atual reflita o sentimento de que as democracias vacilam sob o peso de exigências econômicas, sociais, identitárias e de segurança, que muitas vezes assumem a forma de denúncia das elites e de defesa de um povo virtuoso, a sua essência permanece pouco clara. Por um lado, porque dois níveis de discurso - o dos atores e o dos analistas, sejam eles das ciências sociais ou da política - se misturam nos debates. Por outro lado, porque a natureza transnacional e a diversidade do fenômeno tendem a mascarar as diferenças entre os casos nacionais.

5 A história do populismo na Europa é muito diferente da dos Estados Unidos, do Canadá e da América Latina. No Velho Continente, o populismo geralmente se refere a movimentos de extrema direita (Mudde C., 2007), ou, como disse George Lavau (1970), a uma "função tribunícia" dos partidos de esquerda. Por outro lado, nos Estados Unidos, berço do partido homônimo, o populismo é constituído de uma linguagem política que reflete uma paixão igualitária oriunda da revolução americana (Kazin M., 1995). Quanto à América Latina, muitas vezes considerada como a sua "terra por excelência" (Hermet G., 2001), o que a tornaria o "paradigma do populismo moderno" (Dorna A., 1999), refere-se primeiro a um "populismo de governo" mais que de "denúncia" ou mesmo de "oposição" (Rosanvallon P..., 2011), cuja diversidade de experiências marcou profundamente o século XX do subcontinente (Marques Pereira B., Garibay D., 2011), e cujos legados permanecem fortes nas primeiras décadas do terceiro milênio. Mas a "frequência" e a "imprecisão" do conceito pedem maiores precisões sobre o contexto do seu uso, o que conduz a determinar uma pluralidade de movimentos e de regimes historicamente localizados, e sobretudo porque, salvo algumas excepções, "ninguém se diz ou afirma ser populista" (Rouquié A.,[1987] 1998).

6 Nos Estados Unidos, o populismo tem raízes profundas que remontam à fundação do país. Do ponto de vista teórico, as afinidades entre o primeiro país cuja constituição de 1787 estipula "We The People...Do" e o populismo, que reivindica os princípios básicos da democracia (a regra da maioria e a soberania popular), confirmam até que ponto o populismo segue a democracia como sua sombra (Arditi B., 2004). Mas a relação entre os dois está, no entanto, cheia de tensões, como demonstra abundantemente a história dos Estados Unidos. Desde os anos de 1780, os Pais fundadores federalistas denunciavam a "tirania da maioria", uma expressão que coincide em grande parte com o uso contemporâneo do "populismo". É por isso que a constituição pensada por James Madison e os outros representantes da Filadélfia multiplicaram os "checks and balances" para combater essa tão temida tirania. Desde então, muitos movimentos populistas - de direita e de esquerda - têm criticado estes "contrapesos" institucionais como meio de amordaçar a voz do povo. Como escrevem Yves Mény e Yves Surel (2002), 
os movimentos populistas partilham a ideia de que a democracia significa apenas o poder do povo. Desse modo, aumentam volontariamente o abismo entre os ideais democráticos - pensemos na famosa citação de Lincoln em 1863 enaltecendo o "government of, by, for the people" - e o funcionamento elitista da democracia representativa, como é analisada por uma série de políticos e teóricos "realistas", indo de Joseph Schumpeter a Robert Dahl, Giovanni Sartori, sem esquecer Bernard Manin. Esta crítica é assombrosa na vida política americana e se repete com intervalos regulares, porém com a característica singular de que estes movimentos populistas nunca criticam a própria constituição. Podem exigir a sua reforma (é o caso da esquerda), o seu respeito (é o caso da direita), mas nunca a sua abolição.

7 A particularidade americana reside também no fato de que o populismo está historicamente associado a movimentos progressistas, ao contrário das democracias europeias, onde a grande maioria dos populismos é de direita. De fato, foi um jornalista do Kansas que, em 1890, usou o termo "populismo" pela primeira vez em referência ao People's Party (Partido Popular), um terceiro partido, que se tornou uma força política importante com mais de $8 \%$ dos votos nas eleições para presidente de 1892. O surgimento deste movimento de protesto em meio a uma América rural, em uma época de transição de um capitalismo de proprietários individuais a um capitalismo dominado pelas grandes empresas, alimentou um amplo debate histórico. Com base na Escola de Frankfurt, Richard Hofstadter apresentava o populismo como uma reação irracional e patológica contra a modernização econômica; segundo ele, o populismo ilustrava o "estilo paranóico" da vida política americana cuja direita libertária, incorporada por Goldwater (Hofstadter R., 1955, 1964) ilustrava o potencial. Esta tese, no entanto, foi questionada por historiadores que, na linha de Lawrence Goodwyn, apontaram para a impregnação democrática de um movimento com forte dimensão associativa e cuja influência legislativa também foi visível nas primeiras leis que regem o trabalho na fábrica, mas também em certas leis do New Deal (Goodwyn L., 1978, Postels C., 2007, Sanders E., 1999). Na década de 1930, o populismo assumiu tons ameaçadores e até fascistas com Huey Long e Father Coughlin, mas, como mostra Alan Brinkley, ele manteve uma dimensão democrática e levou Roosevelt e os New Dealers a adotarem importantes reformas sociais (Brinkley A., 1982).

8 De fato, toda a dificuldade advinda da análise do populismo nos Estados Unidos reside em sua grande complexidade durante o século 20. Para Michael Kazin, uma distinção deve ser feita entre o Partido Popular e a linguagem populista (no sentido que o historiador Gareth Stedman Jones dá a este termo) que ele deixou para a vida política americana. Essa linguagem, que coloca um povo virtuoso e trabalhador representando a essência da América contra uma elite de parasitas que a ameaçam, funciona, segundo Kazin, como um substituto de uma retórica de classe assumida, mas os democratas e a esquerda americana não são seus únicos representantes: o populismo tornou-se, a partir dos anos 50, um componente essencial da reconfiguração da direita americana, que o utilizou para criticar as elites intelectuais progressistas e os seus projetos de engenharia social, atraindo assim parte do eleitorado operário. Em um contexto de crescentes tensões relacionadas às lutas pela discriminação racial e sexual no trabalho, às guerras culturais e à crise econômica dos anos 70, o populismo serve à defesa de uma América branca e conservadora. De George Wallace a Ronald Reagan e Pat Buchanan, esse populismo de direita enaltece a América no trabalho e às vezes critica os lobbies da K Street, mas seu conteúdo ideológico e sua relação com as classes sociais permanecem ambíguos, pois levam a reformas que refletem os interesses das elites econômicas e, 
assim, contribuem para a ascensão do neoliberalismo (Kazin M., 1995, 2017, Frank T., 2004).

9 Em suma, a prevalência do populismo nos Estados Unidos ilustra a ausência de qualquer tradição marxista importante - ainda mais marginal após a revolução bolchevique, e depois a Guerra Fria - e o descrédito consequente dos argumentos da classe. No entanto, sua maleabilidade e consolidação à direita por quase sessenta anos também refletem certamente a necessidade de identificar suas ligações com a história social e política da América periurbana e o antiestatismo das classes médias que formam neste país a base eleitoral do Partido Republicano (McGirr L., 2001).

Por estas razões, inserir Donald Trump na trama do populismo americano não é fácil, o que provavelmente explica por que muitos observadores preferem voltar à tese de Hofstadter, que recuperou um certo vigor. Muitos criticaram Trump como uma anomalia na vida política americana, que só conseguiu conquistar o Partido Republicano, e depois a presidência, graças à uma série de circunstâncias. No entanto, o fenômeno Trump é muito mais complexo do que seus discursos sugerem, não apenas porque seu eleitorado, apesar das mudanças a nível local na rust belt, coincide com o eleitorado tradicional do Partido Republicano, mas também porque suas posições contra a imigração e a favor do protecionismo contemplam a política defendida pelo Partido Republicano do final do século 19.

11 Após anos de mobilização conservadora e prontamente populista, Trump pode de fato representar uma forma de exaustão desta "revolução conservadora" das últimas décadas. Mas, acima de tudo, é um exemplo perfeito do que P-A Taguieff define como "populismo-atitude" (1997, p. 15), independente de visões ou tradições mais ou menos estruturadas, politicamente indeterminadas, mas idealizando o "popular". Além disso, a administração Trump é um passo crucial na história americana do populismo, na medida em que já não é apenas um movimento extra-institucional, mas, pelo contrário, está no centro do poder.

12 Na América Latina, por outro lado, a experiência governamental do populismo é muito mais importante. $O$ contexto do surgimento do termo populismo na América Latina está ligado ao desenvolvimento das ciências sociais no subcontinente no final dos anos 1950 e início dos anos 1960. Sociólogos e políticos apropriaram-se então do conceito para analisar os regimes autoritários e nacionalistas que deram origem às políticas de regulação e redistribuição, características da sequência que acabava de terminar (Quattrocchi-Woisson D., 1997).

13 Aplicado pela primeira vez ao peronismo na Argentina (Germani G., 1962; di Tella T., 1964) e ao getulismo no Brasil (Cardoso F.., Weffort F. (eds.), 1970), o conceito se espalhou rapidamente por todo o subcontinente para apreender a conjuntura dos anos 1920 e 1960, durante os quais partidos (como o APRA no Peru, o Partido Revolucionário Febrerista no Paraguai, o MNR na Bolívia), líderes que nunca tiveram acesso ao poder (Cesar Sandino na Nicarágua, Jorge Eliécer Gaitán na Colômbia), governos (México pósrevolucionário, Gualberto Villaroel na Bolívia, Velasco Ibarra no Equador), encarnaram as respostas à crise institucional (ficção democrática) e econômica (modelo agroexportador) das repúblicas oligárquicas. o denominador comum era colocar o "povo" no centro de seus discursos de mobilização, seja o do peronista "sem camisa" na Argentina, os "esquecidos" no Equador sob Velasco Ibarra, os "pobres" no Brasil dirigido por Vargas, os "pés descalços" (pynandí) colorados no Paraguai. 
14 Além da diversidade de experiências nacionais vivenciadas, vários elementos permitem caracterizar as singularidades e a historicidade desses populismos latino-americanos. Em geral, os líderes foram movidos por uma dinâmica democrática associada à extensão do sufrágio e promoveram políticas desenvolvimentistas baseadas na regulação estatal e na redistribuição social. Os discursos de mobilização se basearam em uma dupla polarização: o povo contra as elites, a nação contra os imperialistas. São, de fato, regimes de mobilização alinhados com os movimentos sociais, baseados em uma forte liderança sindical e/ou partidário. Finalmente, a maioria desses regimes se engajaram em uma transformação limitada das estruturas socioeconômicas, com a nacionalização de setores estratégicos que muito raramente resultaram em reforma agrária. Consequentemente, eles chegaram a um frágil equilíbrio ao organizar o "Estado de Compromisso", que deveria preservar a propriedade das elites satisfazendo parcialmente as expectativas sociais dos setores populares e das classes médias.

Regimes de "transição" que se esforçavam para "integrar os setores populares dentro da ordem política" (Rouquié A., 1998) marcaram um passo essencial na construção do processo democrático na América Latina. As convocações das eleições e a ampliação do sufrágio acompanharam a tomada do poder de Perón na Argentina em 1946 e 1952, Estenssoro na Bolívia em 1952 e o retorno de Vargas no Brasil em 1951. Nesse sentido, esses governos "populistas" latino-americanos muitas vezes iniciaram e promoveram políticas indigenistas das primeiras décadas do século XX, com o intuito de forjar a nação, consolidar uma identidade nacional enraizada no território e com bases nativas, mas também integrar o conjunto de setores populares, fossem eles indígenas, afrolatino-americanos (Andrews G. R., 2007), ou mesmo oriundos da imigração.

Os conflitos da década de 1960 deixaram claros os limites ideológicos dos populismos históricos latino-americanos. A via revolucionária cubana, o desejo de mudança social, dentro da qual a reforma agrária foi umas das palavras de ordem, romperam o equilíbrio alcançado com o Estado de compromisso e fraturaram os movimentos, cuja unidade às vezes se baseava unicamente na expressão de lealdade ao líder, já as ditaduras da Guerra Fria dos anos 70 afirmaram que queriam pôr fim à "aberração populista" (Quattrocchi Woisson D., 1997).

17 Quanto aos governos reformistas dos anos 2000/2010, mais uma vez qualificados como "populistas" por seus críticos (Panizza F., 2008), eles só podem ser considerados de forma muito limitada como herdeiros dos regimes do século passado; a filiação com os "velhos populismos" sendo ainda mais problemática quando se trata de "neopopulismos" contemporâneos articulando um apelo ao povo e a implementação de políticas neoliberais e de apoio às grandes corporações. Contudo, os primeiros foram, antes de tudo, o fruto da consolidação democrática, que pôs fim às ditaduras da Guerra Fria, e da alternância que se seguiu à crise social provocada por duas décadas de políticas de ajustamento estrutural e de desregulamentação neoliberal.

18 Além das políticas redistributivas e de uma ação efetiva contra a pobreza iniciada nos anos 2000 pelos governos de esquerda, alguns líderes certamente retornaram a um poder personalista, divisor e com as práticas de contato imediato com "o povo", mas articulando em paralelo a ação governamental com organizações de base, sejam elas associativas, comunitárias, sindicais ou comunais. Estes últimos elementos podem caracterizar esses novos "populismos" latino-americanos. Mas, ao contrário de seus antecessores policlassistas e "nacional-populares", eles operaram em um contexto 
democrático consolidado e se posicionaram claramente à esquerda na cena política nacional e internacional.

Em suma, há algum modelo populista? Americano? Ou poderíamos evocar sobretudo um laboratório americano, com diversas experiências populistas e muitas singularidades nacionais, que questionam especialmente as ligações entre populismo e construção democrática; entre populismo e eleitoralismo; entre populismo e participação?

Este número de IdeAs oferece uma nova perspectiva sobre a questão ao mostrar, a partir de estudos de caso locais, como os historiadores, sociólogos e políticos que trabalham sobre a América do Sul e do Norte empregam a noção de populismo tendo em vista os fenômenos sociais, políticos e econômicos que graças a ela podem ser racionalizados. O que diferencia, numa democracia, o populismo do apelo ao voto dos eleitores e, em particular, o das classes trabalhadoras? Como escreveram Yves Mény e Yves Surel (2002), os movimentos populistas expressam-se e comportam-se como se a democracia fosse reduzida ao poder do povo.

Mas esse diagnóstico geral precisa ser afinado, pois os populismos, longe de estarem em oposição sistemática à sofisticação da democracia liberal e representativa (Manin, B., 2005), são encontrados ao longo de um continuum. $O$ populismo pode, às vezes, assumir formas que são tóxicas para a democracia, mas pode também, sob outras formas, alcançar o que James Morone (1990) chama de "desejo democrático" (Democratic Wish). É por isso que, como explica Joseph Lowndes no seu capítulo do Oxford Handbook of Populism (2017), "é provavelmente melhor analisar o populismo pelo que ele faz do que pelo que é"([it is] perhaps better then to analyze not what populism was but what populism did). Nesta perspectiva, o objetivo desta edição é contribuir para identificar critérios populistas a partir de experiências e análises tiradas do continente americano, do Canadá ao Cone Sul.

\section{BIBLIOGRAFIA}

Andrews, George Reid, Afro-Latinoamérica, 1800-2000, Madrid/Frankfurt am Main, Iberoamericana/Vervuert, 2007.

Arditi, Benjamin, "Populism as a Spectre of democracy", Political Studies, vol.52, n¹, mars 2004, p.135-143.

Brinkley, Alan, Voices of Protest: Huey Long, Father Coughlin and the Great Depresssion, New York: Knopf, 1982.

Canovan, Margaret, "Two Strategies for the Study of Populism”, Political Studies, vol.30, $\mathrm{n}^{\circ} 4$, 1982.

Cardoso, Fernando Enrique y Weffort, Francisco, (Eds.), América latina. Ensayos de interpretación sociológico-política, Santiago de Chile, Editorial Universitaria, 1970. 
Chazel, Laura, «De l'Amérique latine à Madrid : Podemos et la construction d'un «populisme de gauche», Revue Pôle Sud, n50, 2019, p. 121-138.

Di Tella, Torcuato, El sistema político argentino y la clase obrera, Buenos Aires, Eudeba, 1964.

Dorna, Alexandre, Le populisme, Paris PUF, 1999.

Frank, Thomas, What's the Matter With Kansas? New York, Holt, 2004.

Freidenberg, Flavia, La tentación populista. Una vía al poder en América latina, Madrid, Editorial Sintésis, 2007.

Germani, Gino, Política y sociedad en una época de transición. De la sociedad tradicional a la sociedad de masas, Buenos Aires, Paidós, 1962.

Goodwyn, Lawrence, Democratic Promise: The Populist Moment in America, New York, Oxford UP, 1976.

Hermet, Guy, Les populismes dans le monde, Paris, Fayard, 2001.

Hofstadter, Richard, The Age of Reform: From Bryan to FDR, New York, Knopf, 1955.

Hofstadter Richard, The Paranoid Style in American Politics, New York, Vintage, 1964.

Kaltwasser, Cristóbal Rovira \& al. (eds.). The Oxford Handbook of Populism, Oxford: Oxford University Press, 2017

Kazin, Michael, The Populist Persuasion, Ithaca, Cornell UP, 1995. Nouvelle édition en 2017.

Laclau, Ernesto, La raison populiste, Paris, Seuil, 2008.

Lowndes, Joseph, «Populism in the United States», p.232-246, in Cristobal R. Kaltwasser, et al., The Oxford Handbook of Populism, Oxford, Oxford University Press, 2017.

McGirr, Lisa, Suburban Warriors, The Origins of the New American Right, Princeton, Princeton UP, 2001.

Marques-Pereira, Bérengère, Garibay, David, La politique en Amérique latine. Histoires, institutions et citoyennetés, Paris, Armand Colin, 2011.

Manin, Bernard, The Principles of Representative Government, Cambridge, Mass., Cambridge University Press, 2005.

Morone, James, The Democratic Wish. Popular Participation and the Limits of American Government, New York, Basic Books, 1990.

Mudde, Cas, Populist Radical Right Parties in Europe, Cambridge,UK, Cambridge UP, 2007.

Panizza, Francisco, «Fisuras entre Populismo y Democracia en América Latina», Stockholm Review of Latin American Studies, n³, 2008, p. 81-93.

Postels, Charles, The Populist Vision, New York, Oxford, 2007.

Quattrocchi-Woisson, Diana, «Les populismes latino-américains à l'épreuve des modèles d'interprétation européens», Vingtième siècle, revue d'histoire, n56, 1997, p. 161-183.

Rosanvallon, Pierre, «Penser le populisme», laviedesidees.fr, 2011.

Rouquié, Alain, Amérique latine. Introduction à l'extrême-Occident, Paris, Seuil, 1998 [1987 1ère édition]

Sanders, Eilzabeth, Roots of Reform, Farmers, Workers, and theAmerican State, 1877-1917, Chicago, The University of Chicago Press, 1999. 
Surel,Yves, Mény, Yves, 'Populism: The Pathology of Democracy?', in Democracies and the Populist Challenge, London: Palgrave, 2002, 3-6.

Taguieff, Pierre-André, «Le populisme et la science politique: du mirage conceptuel aux vrais problèmes», Vingtième Siècle, n56, octobre-décembre 1997, p.4-33.

Wiles, Peter, «A Syndrome, Not a Doctrine: Some Elementary Theses on Populism», in Ghita Ionescu, Ernest Gellner, ed., Populism. Its Meaning and National Characteristics, London, Weidenfeld and Nicolson, 196

\section{NOTAS}

1. «Mélenchon, le populisme assumé », France Inter, L'édito politique, 29 agosto de 2017 : <https://www.franceinter.fr/emissions/l-edito-politique/l-edito-politique-29aout-2017>.

2. Pierre Rosanvallon, «Penser le populisme», 27 de setembro de 2011: http:// www.laviedesidees.fr/Penser-le-populisme.html.

\section{AUTORES}

\section{LUC CAPDEVILA}

(Universidade de Rennes 2 - ARENES)

\section{FRANÇOIS VERGNIOLLE DE CHANTAL}

(Universidade de Paris - LARCA, UMR 8225)

\section{JEAN-CHRISTIAN VINEL}

(Universidade de Paris - LARCA, UMR 8225) 